\title{
Local Tissue Electrical Resistances in Transpedicular Screw Application in the Thoracolumbar Region
}

\author{
Yahya TURAN ${ }^{1}$, Murat SAYIN², Alaattin YURT ${ }^{3}$, Tevfik YILMAZ¹, Fusun DEMIRCIVI OZER ${ }^{4}$, Cuneyt TEMIZ ${ }^{5}$ \\ ${ }^{1}$ Dicle University, School of Medicine, Department of Neurosurgery, Diyarbakır, Turkey \\ ${ }^{2}$ Izmir Katip Celebi University, School of Medicine, Atatürk Training and Research Hospital, Department of Neurosurgery, İzmir, Turkey \\ ${ }^{3}$ Izmir Bozyaka Training and Research Hospital, Department of Neurosurgery, İzmir, Turkey \\ ${ }^{4}$ Izmir Tepecik Training and Research Hospital, Department of Neurosurgery, İzmir, Turkey \\ ${ }^{5}$ Celal Bayar University, School of Medicine, Department of Neurosurgery, Manisa, Turkey
}

\section{ABSTRACT}

AIM: To determine local tissue electrical resistance differences generated during a screw pass from the pedicle to another tissue rather than determining all individual electrical tissue resistance values.

MATERIAL and METHODS: We attempted to measure electrical resistance values of regional tissues in addition to fluoroscopic imaging during application of fixation via a transpedicular screw. We also attempted to detect local tissue electrical resistance alterations in case of malposition of the screw inside the pedicle. For this purpose, local tissue electrical resistances of 10 transpedicular tracks opened with standard track openers bilaterally in 5 vertebrae, and of spinal cord accessed by puncturing the medial walls of three vertebrae in a cadaver were measured. These resistance differences were not only measured in human cadaveric tissue but also in 36 pedicles belonging to a total of 18 vertebrae between Th 1-S1 vertebrae of a sheep cadaver. Both medial and lateral walls were drilled to measure local tissue resistance differences in a sheep cadaver.

RESULTS: Our results indicated that local tissue electrical resistance changes were statistically significant in both human and sheep cadaver.

CONCLUSION: It is possible to prevent screw malposition using a simple and cheap electrical resistance measurement. Local tissue electrical resistance measurement during transpedicular screw insertion is a safe, simple, cheap, and practical method.

KEYWORDS: Spinal impedance, Transpedicular screw, Thoracolumbar region, Screw malposition, Spinal surgery

\section{INTRODUCTION}

$\mathrm{T}$ Transpedicular screw application has an important place in common spinal operations. Inadvertent perforation of the wall of the vertebral pedicle is a well-known complication associated with standard pedicle screw insertion procedure. Despite varying rates by detection criteria, it has been reported that more than $25 \%$ of screws are malpositioned $(9,10,15,22)$. Malpositioned screws may have serious clinical consequences from dysesthesia to paraplegia (although rare) $(6,8,17,26,28,29)$. Many techniques have been defined for this purpose, including somatosensorial evoked potentials, elec- tromyography, surgical navigation, and robotic surgery $(11,12$, $18,20,22,27)$. However, each technique has its own advantages and disadvantages. None of the techniques is simple enough and adequate on its own.

Advanced techniques such as neuronavigation and fluoronavigation may be performed only in a few centers since they are both too costly and impractical although they minimize complication rates. Therefore, anteroposterior (AP) and lateral fluoroscopic imaging are currently the most commonly used complementary methods for transpedicular screw application. Transpedicular screw malposition remains a serious problem 
with fluoroscopic imaging. Fluoroscopy does not provide adequate safety (particularly because the scapulae are superimposed at the upper thoracic level). To overcome this problem, neuromonitorization systems have been developed, which give information only after damage.

In this study, electrical resistances of bone and other neighboring tissue were measured as a complementary method to fluoroscopic imaging. The aim of this study was to determine local tissue electrical resistance differences generated during a screw pass from the pedicle to another tissue rather than determining all individual electrical tissue resistance values. As a result, we aimed to define a new criterion to determine that the screw is within the bone before damage occurs without concomitant radiation exposure of both the patient and surgeon.

\section{MATERIAL and METHODS}

The cadaver of a woman who died from myocardial infarction at Manisa Psychiatric Hospital 14 days ago was used. The cadaver was placed on a Philips Somatom Emotion brand spiral computed tomography table in the prone position. After distance determination using tomographic images, the vertebral body was accessed via the transpedicular route using a standard drill and track openers. Then, a standard $18 \mathrm{G}$ (green) branule intravenous (IV) catheter tip was placed in the opened transpedicular tracks. In addition, a separate standard $18 \mathrm{G}$ (green) branule IV catheter tip was also placed $1 \mathrm{~mm}$ deep on the facet joint that was the starting point of the pedicles for each transpedicular track (Figure 1). As a next step, local tissue electrical resistance measurement was performed with a multimeter model Digital Multimeter MY64 using the needles inside the branule tips in the transpedicular track and on the facet joint. This device can be used as a voltmeter, ammeter, and an ohmmeter. We used the ohmmeter part.

Computed tomographic images were used to verify that the transpedicular tracks opened with standard drills and track openers at the level of Th 4, Th 7, Th 11, L3, and S 1 vertebrae were bilaterally in the correct anatomical localizations in the female cadaver (Figure 2). Hence, a total of 10 entries were bilaterally done in 5 vertebral pedicles. Then, the medial walls of the pedicles at the left side at the level of Th 4 and Th 11 and at the right side at the level of L3 were drilled with standard drills and track openers (Figure 3 ) and the spinal cord was accessed. Simultaneously, the same assembly was used to measure electrical local tissue resistance. Hence, 3 vertebrae had their medial pedicle wall drilled for a total of 3 times.

The same procedures were repeated in a 6-hour cadaver of a 1-year-old sheep using the same assembly (Figures 4-6). Computed tomographic images were used to verify that the transpedicular tracks opened with standard drills and track openers in a total of 18 vertebrae between the levels of Th1-S1 were bilaterally in the correct anatomical localizations in the sheep cadaver (Figures 7,8).

As a next step, local tissue electrical resistance measurement was performed with a multimeter model Digital Multimeter

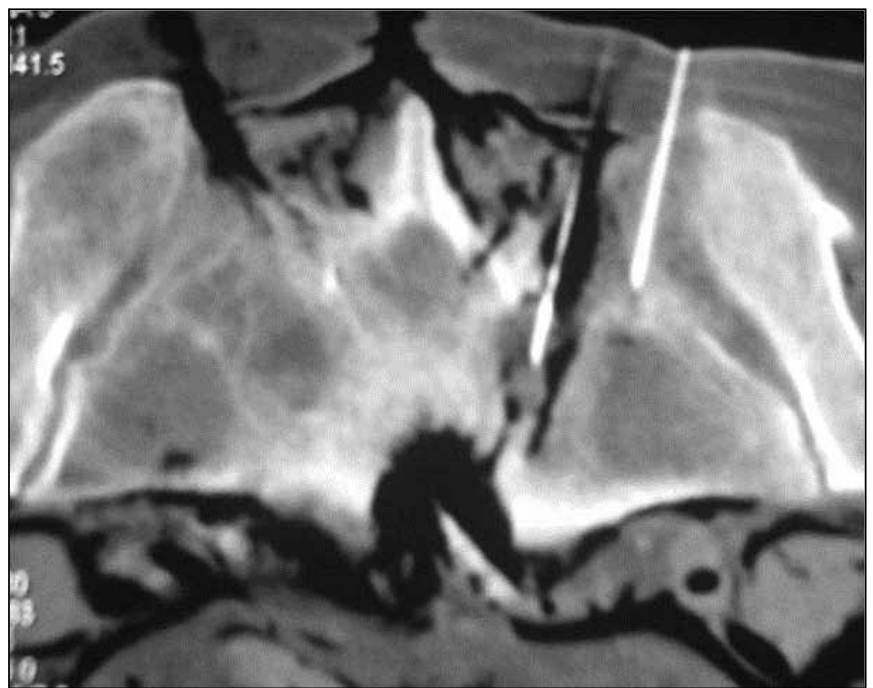

Figure 1: Both branule IV catheter tips are seen in S1 in the female cadaver.

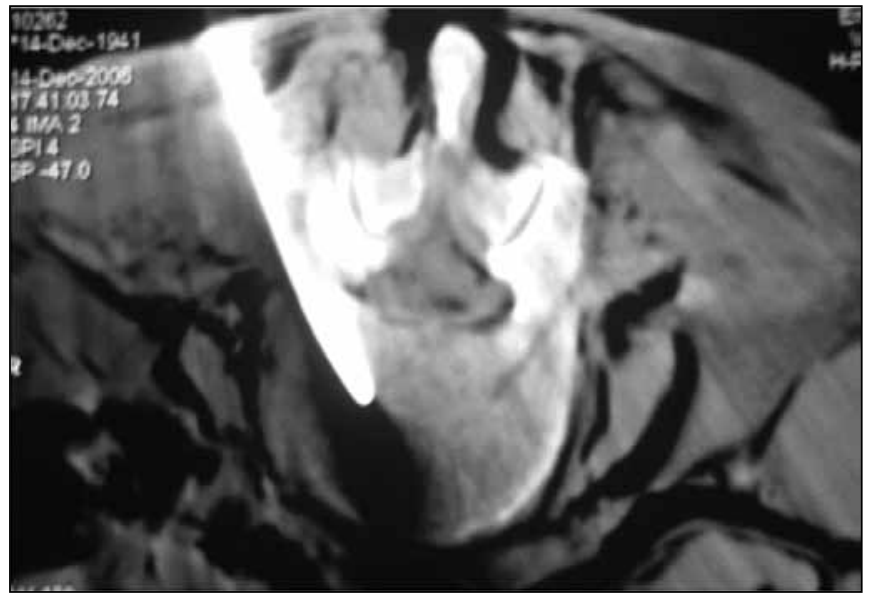

Figure 2: View of the right pedicle of L3 while being entered with the standard track opener in the female cadaver.

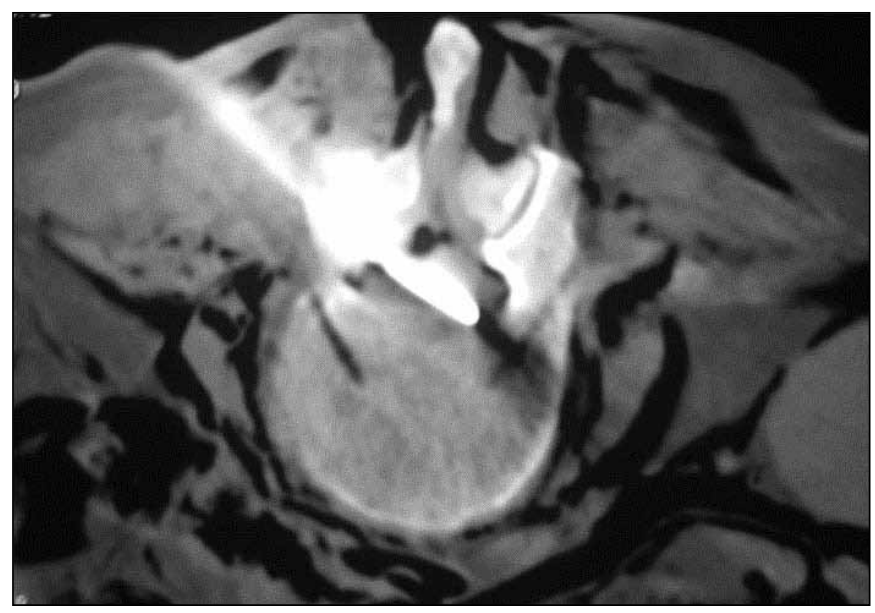

Figure 3: Medial wall of the right pedicle of L3 is drilled and spinal cord is accessed with standard track opener in the female cadaver. 


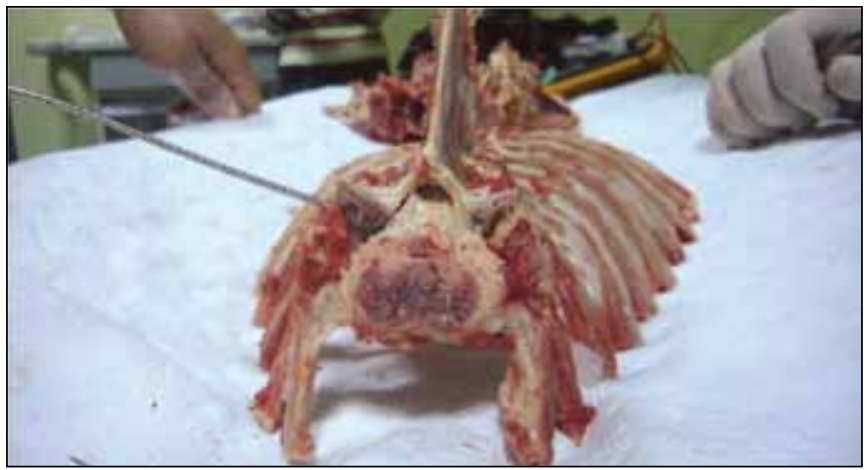

Figure 4: Right pedicle of the Th 1 is being entered in the sheep cadaver.

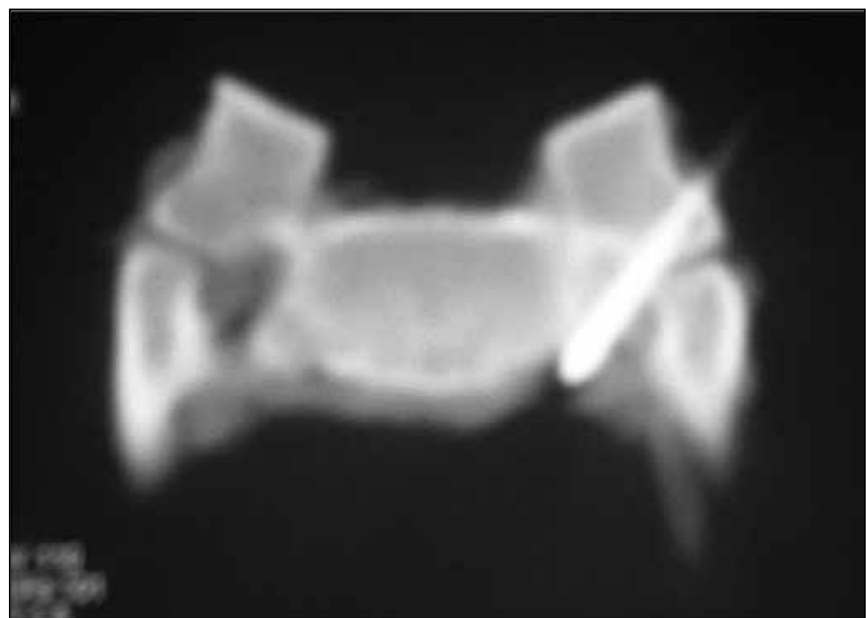

Figure 6: View of the standard track opener having drilled the lateral wall of the left pedicle of Th 1 of the sheep cadaver.

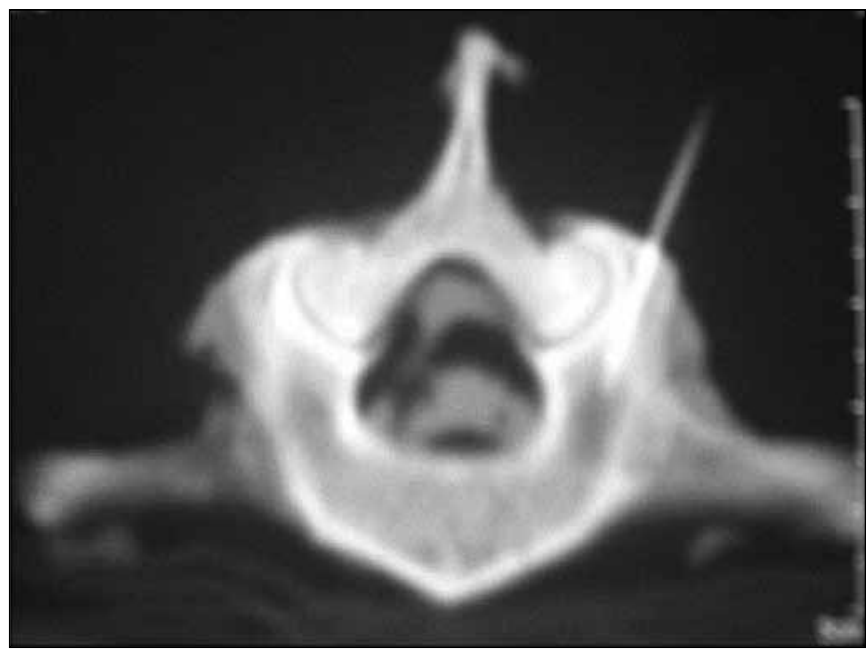

Figure 8: View of the branule IV catheter tip inside the left pedicle of L5 of the sheep cadaver.

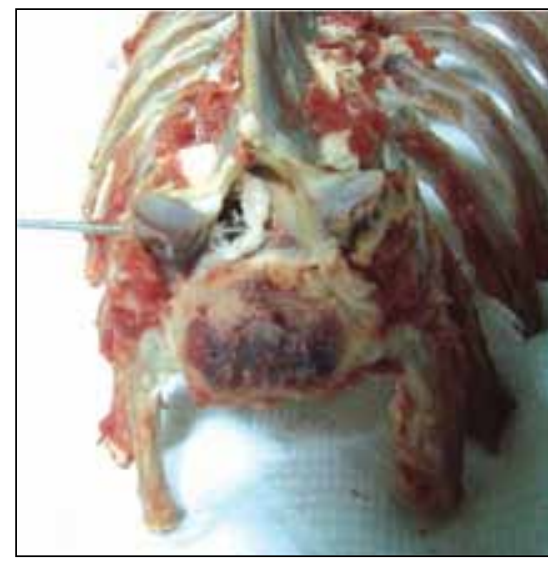

Figure 5: Medial wall of the right pedicle of Th 1 is drilled and spinal cord is accessed with standard track opener in the sheep cadaver.

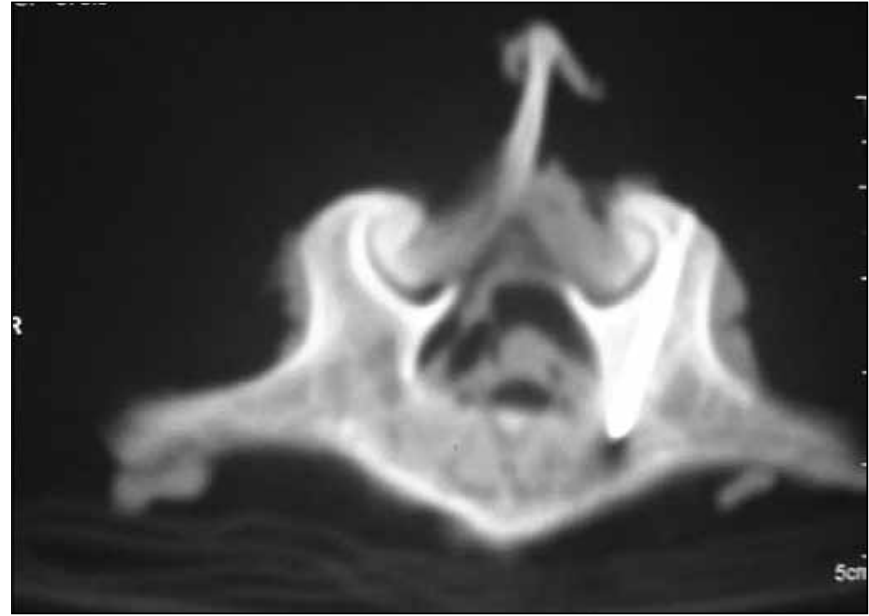

Figure 7: View of the standard track opener inside the left pedicle of L5 of the sheep cadaver.

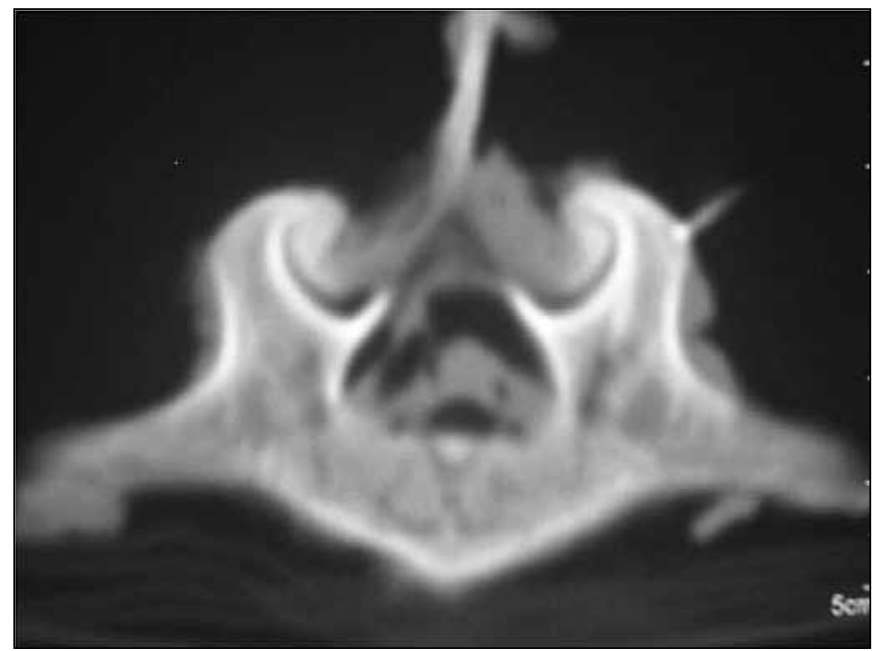

Figure 9: View of the second branule IV catheter tip inside facet joint of L5 of the sheep cadaver. 
MY64 using the needles inside the standard $18 \mathrm{G}$ (green) branule IV catheter tips placed in these transpedicular tracks and standard $18 \mathrm{G}$ (green) branule IV catheter tips of the same brand placed on the facet joint (Figure 9). In this way, a total of 36 entries were done into 18 vertebral pedicles. Then, medial pedicle walls were drilled bilaterally and the spinal cord was accessed at the same levels using standard drills and track openers again. Meanwhile, electrical local tissue resistances were measured with the same assemblies. Hence, medial pedicle walls of 18 vertebrae were drilled for a total of 36 times. Then, lateral pedicle walls were drilled bilaterally with standard drills and track openers and electrical local tissue resistance of that region (muscle) were measured at all levels between Th 1 and S1. Hence, lateral pedicle walls of 18 vertebrae were drilled for a total of 36 times.

\section{RESULTS}

Table I shows digital multimeter-measured local tissue electrical resistance values of the medial wall of 5 bilaterally drilled vertebral pedicles at the level of Th 4 , Th 7, Th 11, L3, and S 1 with a total of 10 drills, and of a total of 3 vertebral pedicles drilled from the left at the level of Th 4 and Th 11 and from the right at the level of L3 with standard techniques in a 14-day cadaver of a 67 -year-old woman.

Statistical analysis of study data was performed with SPSS 14.0 for Windows software package at the Ege University Faculty of Medicine's Department of Biostatistics.

The Mann-Whitney $U$ test was used for analysis of data from the female cadaver. Using this method, we compared local tissue electrical resistance values of the pedicle wall and spinal cord accessed via the drilled medial wall. The mean resistance value of the intact pedicle was $7.56 \mathrm{Ohm}$ while the mean resistance value of the drilled medial wall of the pedicle (vertebra) was $13.65 \mathrm{Ohm}$.

Under the light of the above data, the intact pedicle wall and spinal cord accessed via a drilled medial wall were significantly different with respect to local tissue electrical resistance values $(p=0.025)$.

Table II shows digital multimeter-measured local tissue electrical resistance values of the medial wall of 18 bilaterally drilled vertebral pedicles at the level of Th1-S1 with a total of 36 drills, and of the region accessed via drilled lateral wall (muscle) of a total 36 pedicles at all levels between Th1 and S1 levels with standard techniques in a 6-hour cadaver of a 1-year-old sheep.

Analysis of the data from the sheep cadaver was performed with the SPSS 14.0 for Windows software package using Analysis of Variance for Repeated measures (Repeated Measures ANOVA).

Since all local tissue electrical resistance values of spinal cord accessed via a drilled medial wall in the sheep cadaver exceeded the selected upper limit of $20 \mathrm{Ohm}$, all results were obtained as 1 (i.e. over $20 \mathrm{Ohm}$ ). As all these values were the same and considerably higher than local tissue electrical values of the intact pedicle, their comparison with local tissue electrical values of the intact pedicle was accepted as statistically significant.

Local tissue electrical resistance values of the intact pedicle wall and the region accessed via the drilled lateral wall (muscle) in the sheep cadaver were compared against each other using the Analysis of Variance for Repeated Measures. They were also compared as right and left. The mean local tissue electrical resistance value of the intact pedicle wall was 1.80 Ohm while the mean resistance value of the region accessed via the drilled lateral wall (muscle) was $0.61 \mathrm{Ohm}$. Under the light of all these results, it was found that no significant difference existed between right and left resistances. However, comparison of the local tissue electrical resistance values of the intact pedicle wall and the region accessed via drilled lateral wall (muscle) revealed a significant difference ( $p$ $<0.001)$.

\section{DISCUSSION}

Despite its frequent use, transpedicular screw application is not as simple and innocent as it is once thought to be. Depending on the detection criteria, the rate of screw malposition has been reported to be $1.2 \%-28.8 \%(9,10,15$, 22). Serious clinical outcomes from dysesthesia to paraplegia may occur due to malposition during screw application at the upper lumbar and thoracic regions $(6,8,17,26,28,29)$.

Table I: Local Tissue Electrical Resistance Values (Ohm) of Pedicular Tracks Opened and Medial Wall Drilled with a Standard Technique in the Vertebra of a 14-Day Cadaver of a 67-Year-Old Woman

\begin{tabular}{lcccc}
\hline Side & \multicolumn{2}{c}{ Pedicle } & Redial Wall \\
\cline { 2 - 5 } Level & Right & Left & Left \\
\hline Th 4 & $6.69-7.27$ & $6.85-7.42$ & $12.69-12.85$ \\
\hline Th 7 & $7.25-7.53$ & $7.48-7.64$ & \\
\hline Th 11 & $7.95-8.40$ & $7.90-8.40$ & & $13.55-13.75$ \\
\hline L 3 & $7.15-7.30$ & $7.50-8.30$ & $14.55-14.75$ & \\
\hline S 1 & $7.98-8.40$ & $7.95-8.20$ & & \\
\hline
\end{tabular}

Th: Thoracic, L: Lumbar, S: Sacral. 
Currently, transpedicular screw applications mainly have outcomes proportional to two-sided fluoroscopic imaging and the surgeons' experience. In various cadaveric studies on bone, neural tissue, and muscle groups in the whole vertebral column, thoraco-lumbar junction being at the first place, it has been evident that there exist some anatomic variations from person to person (7). Thus, the reliability of the measurements of standard pedicle axis angle, pedicle width, pedicle length, and the distance between anterior vertebral cortex and transpedicular screw insertion hole is limited (16).

Various methods related to pedicle position and screw malposition have been developed to allow safer screw insertion in a patient positioned on the operation table; their use depends on the surgeon. Many techniques have been defined for this purpose, including somatosensorial evoked potentials, electromyography, surgical navigations, and robotic surgery $(11,12,18,20,22,27)$. However, each technique has its own advantages and disadvantages. None of them is simple and adequate on its own. Each of these techniques aims at pedicle navigation while they also have some limitations. Somatosensorial evoked potential is not adequate for evaluation of nerve roots during screw insertion
(12). Electromyography localizes nerve roots but requires a neurologist while the pedicle is determined, and furthermore it is an invasive technique (27). Intraoperative use of $X$ rays causes excessive $X$ ray exposure of both the surgical team and the patient. Another method, computed tomography assisted surgical navigation, has limited value since it is timeconsuming, requires training and experience, and is highly expensive. It is also dependent on preoperative computed tomography sections and intraoperative simultaneous imaging difficult to perform with this method (11).

Electrical resistances also vary by tissues of human body. Neural, bone, and muscular tissues have differing electrical resistance values $(1,4,13)$. Our study was based on that simple physical fact.

Local tissue electrical resistance measurement has been used in various settings. It is commonly used to diagnose obesity in clinical practice and determination of lean body mass in athletes by measuring the electrical permeability difference of lean tissue mass and fat. Body fat ratio can be measured by means of bioelectrical impedance $(1,4,13,21)$. In addition to ultrasonography, methods such as bioelectrical impedance

Table II: Local Tissue Electrical Resistance Values (Ohm) of Pedicular Tracks Opened and Lateral Wall Drilled with a Standard Technique in the Vertebra of a 6-Hour Cadaver of a 1-Year-Old Sheep

\begin{tabular}{|c|c|c|c|c|}
\hline \multirow{2}{*}{$\begin{array}{l}\text { Side } \\
\text { Level }\end{array}$} & \multicolumn{2}{|c|}{ Pedicle } & \multicolumn{2}{|c|}{ Lateral Wall } \\
\hline & Right & Left & Right & Left \\
\hline Th 1 & $2.20-2.40$ & $2.24-2.36$ & 0.55 & 0.57 \\
\hline Th 2 & $2.17-2.35$ & $2.16-2.36$ & 0.56 & 0.56 \\
\hline Th 3 & $2.18-2.28$ & $2.18-2.30$ & 0.60 & 0.59 \\
\hline Th 4 & $2.24-2.29$ & $2.24-2.30$ & 0.58 & 0.62 \\
\hline Th 5 & $2.30-2.42$ & $2.32-2.38$ & 0.61 & 0.59 \\
\hline Th 6 & $2.42-2.64$ & $2.42-2.60$ & 0.61 & 0.60 \\
\hline Th 7 & $2.40-2.72$ & $2.40-2.70$ & 0.59 & 0.61 \\
\hline Th 8 & $2.53-2.67$ & $2.55-2.65$ & 0.61 & 0.63 \\
\hline Th 9 & $2.65-2.82$ & $2.65-2.82$ & 0.63 & 0.64 \\
\hline Th 10 & $2.76-2.93$ & $2.77-2.90$ & 0.59 & 0.59 \\
\hline Th 11 & $2.83-3.09$ & $2.85-2.98$ & 0.64 & 0.63 \\
\hline Th 12 & $2.98-3.05$ & $3.00-3.08$ & 0.59 & 0.59 \\
\hline $\mathbf{L} 1$ & $3.06-3.19$ & $3.07-3.24$ & 0.63 & 0.63 \\
\hline $\mathbf{L} 2$ & $3.14-3.46$ & $3.13-3.42$ & 0.65 & 0.65 \\
\hline L 3 & $3.09-3.23$ & $3.11-3.24$ & 0.61 & 0.63 \\
\hline$\underline{L} 4$ & $3.14-3.56$ & $3.20-3.45$ & 0.63 & 0.64 \\
\hline $\mathbf{L} 5$ & $3.28-3.54$ & $3.20-3.50$ & 0.62 & 0.63 \\
\hline S 1 & $3.31-3.80$ & $3.42-3.85$ & 0.65 & 0.65 \\
\hline
\end{tabular}

Th: Thoracic, L: Lumbar, S: Sacral. 
have also been employed to diagnose fatty liver disease (19). In blood products stored at blood banks, $\mathrm{Na}^{+}, \mathrm{K}^{+}$ion efflux alterations also change the electrical impedance of blood (24). Malnutrition may, independent of respiratory functions, decrease protein synthesis in chronic obstructive pulmonary disease (COPD) and lead to a reduction in body fat and muscle mass, a condition that can be quantified by calculating lean body mass with bioelectrical impedance measurement (23). Some studies have examined the effect of the difference of the electrode's impedance on the threshold value used for transcranial electrical stimulation during evoked motor potential monitorization (14).

Gundanna et al. conducted a preliminary study on the importance of the somatosensorial evoked potential measurement during transpedicular screw insertion. However, somatosensorial evoked potential was found to be unraveling in the assessment of nerve roots during screw insertion (12).

Darden et al. compared electromyography and local tissue resistance measurement with respect to detection of pedicle wall injury and reported that electromyography was more sensitive. However, it is not always possible to work with intraoperative electromyography and a neurologist as in that study (5).

Shi et al. performed a study with electrical stimulation on the intraoperative evaluation of transpedicular screw insertion. They reported that evoked electromyographic records were able to detect pedicle perforation. However, it may not always be feasible to employ a neurologist with fine electrophysiology knowledge to obtain those records (25).

In a preliminary study assessing the reliability of measurement of local tissue electrical resistance and electromyographic measurement assessing muscle contractions on the detection of iatrogenically created pedicle perforation, Bolger et al. reported results similar to ours. However, that study was performed on pigs and, as the researchers pointed, vertebral anatomy and localization of nerve roots are different in pigs than in humans. Thus, further studies are needed to define the benefits of measurement of electromyographic muscle contractions and electrical resistances $(2,3)$.

Each of the studies performed so far has its own advantages and disadvantages. None of them is cheap, practical, simple, and adequate on its own. The need for an experienced neurologist in every case is a particular disadvantage. Moreover, although advanced applications such as neuronavigation and fluoronavigation minimize the complication rate, they are used in only a few centers since they are both too costly and impractical. Thus, 2-sided fluoroscopic imaging is still the most commonly used complementary method. Transpedicular screw malposition continues to be a major problem with fluoroscopic imaging. It cannot provide adequate safety since the scapulae are superimposed at upper thoracic region. To solve this problem, neuromonitorization techniques have been developed. However, they provide information only after the tissue sustains damage. We therefore aimed to invent a new technique with no radiation exposure, which can be safely used even in the upper level vertebrae, detect screw entry into the pedicle before neural damage occurs, and give a warning as soon as pedicle damage ensues so that the track opener can be immediately pulled back and re-introduced at the desired anatomical route.

The aim of this study was to determine local tissue electrical resistance differences generated during a screw pass from the pedicle to another tissue rather than determining all individual electrical tissue resistance values. These resistance differences were not only measured in human cadaveric tissue, but also in all vertebral levels including the upper thoracic vertebrae of a sheep cadaver. Furthermore, such a study was performed in a cadaver for the first time.

Our results showed that local tissue electrical resistance changes were significant in both human and sheep cadavers. This means that it appears possible to prevent screw malposition using a simple and cheap electrical resistance measurement technique. Damage to neural tissue is prevented by the very low direct electrical current value used during measurements. Connecting this measurement device to penetrating devices and slow advancement of the penetrating device inside the pedicle with simultaneous, continuous (or recording at very frequent intervals of every 0.5 seconds) monitorization of local tissue electrical resistance may allow desired safe screw insertion. Slow advancement of the track opener is of utmost importance since the electrical resistance is measured from the tip of the track opener. In case of entry into a different tissue, the electrical resistance will be altered and the track opener will be pulled back and re-introduced at the desired anatomical route.

\section{CONCLUSION}

Our study suggests that local tissue electrical resistance measurement during transpedicular screw insertion is a safe technique for both the surgeon and patient in terms of radiation exposure, and it offers a simple, cheap, and practical solution. Most importantly, our results suggest that it has the potential to prevent neurological deficits.

\section{- REFERENCES}

1. Baumgartner RN, Chumlea WC, Roche AF: Bioelectric impedance for body composition. Exerc Sport Sci Rev 18:193-224, 1990

2. Bolger C, Carozzo C, Roger T, McEvoy L, Nagaria J, Vanacker G, Bourlion M: A preliminary study of reliability of impedance measurement to detect iatrogenic initial pedicle perforation (in the porcine model). Eur Spine J 15(3): 316-320, 2006

3. Bolger C, Kelleher MO, McEvoy L, Brayda-Bruno M, Kaelin A, Lazennec JY, Le Huec JC, Logroscino C, Mata P, Moreta P, Saillant G, Zeller R: Electrical conductivity measurement: A new technique to detect iatrogenic initial pedicle perforation. Eur Spine J 16(11): 1919-1924, 2007

4. Chumlea WC, Guo SS: Bioelectrical impedance and body composition: Present status and future directions. Nutr Rev 52(4): 123-131, 1994

5. Darden BV, 2nd, Owen JH, Hatley MK, Kostuik J, Tooke SM: A comparison of impedance and electromyogram measurements in detecting the presence of pedicle wall breakthrough. Spine (Phila Pa 1976) 23(2): 256-262, 1998 
6. Davne SH, Myers DL: Complications of lumbar spinal fusion with transpedicular instrumentation. Spine (Phila Pa 1976) 17 Suppl 6: S184-189, 1992

7. Ebraheim NA, Xu R, Darwich M, Yeasting RA: Anatomic relations between the lumbar pedicle and the adjacent neural structures. Spine (Phila Pa 1976) 22(20): 2338-2341, 1997

8. Esses SI, Sachs BL, Dreyzin V: Complications associated with the technique of pedicle screw fixation. A selected survey of $A B S$ members. Spine (Phila Pa 1976) 18(15): 2231-2238; discussion 2238-2239, 1993

9. Garfin SR: Spinal fusion: The use of bone screws in the vertebral pedicles. Summation. Spine (Phila Pa 1976) 19 Suppl 20: 2300S-2305S, 1994

10. Gertzbein SD, Robbins SE: Accuracy of pedicular screw placement in vivo. Spine (Phila Pa 1976) 15(1):11-14, 1990

11. Glossop ND, Hu RW, Randle JA: Computer-aided pedicle screw placement using frameless stereotaxis. Spine (Phila $\mathrm{Pa}$ 1976) 21(17): 2026-2034, 1996

12. Gundanna M, Eskenazi M, Bendo J, Spivak J, Moskovich R: Somatosensory evoked potential monitoring of lumbar pedicle screw placement for in situ posterior spinal fusion. Spine J 3(5): 370-376, 2003

13. Houtkooper LB, Lohman TG, Going SB, Howell WH: Why bioelectrical impedance analysis should be used for estimating adiposity. Am J Clin Nutr 64 Suppl 3: 436S-448S, 1996

14. Journee HL, Polak HE, de Kleuver M: Influence of electrode impedance on threshold voltage for transcranial electrical stimulation in motor evoked potential monitoring. Med Biol Eng Comput 42(4): 557-561, 2004

15. Krag $\mathrm{MH}$ : Biomechanics of thoracolumbar spinal fixation. A review. Spine (Phila Pa 1976) 16 Suppl 3: S84-99, 1991

16. Krag MH, Weaver DL, Beynnon BD, Haugh LD: Morphometry of the thoracic and lumbar spine related to transpedicular screw placement for surgical spinal fixation. Spine (Phila Pa 1976) 13(1): 27-32, 1988

17. Lonstein JE, Denis F, Perra JH, Pinto MR, Smith MD, Winter RB: Complications associated with pedicle screws. J Bone Joint Surg Am 81(11): 1519-1528, 1999

18. Montes E, De Blas G, Regidor I, Barrios C, Burgos J, Hevia E, Palanca JM, Correa C: Electromyographic thresholds after thoracic screw stimulation depend on the distance of the screw from the spinal cord and not on pedicle cortex integrity. Spine $J$ 12(2): 127-132, 2012
19. Naboush A, Hamdy O: Measuring visceral and hepatic fat in clinical practice and clinical research. Endocr Pract 19(4): 587589,2013

20. Ortmaier T, Weiss H, Dobele S, Schreiber U: Experiments on robot-assisted navigated drilling and milling of bones for pedicle screw placement. Int J Med Robot 2(4):350-363, 2006

21. Sagun G, Oguz A, Karagoz E, Filizer AT, Tamer G, Mesci B: Application of alternative anthropometric measurements to predict metabolic syndrome. Clinics (Sao Paulo) 69(5):347-353, 2014

22. Sapkas GS, Papadakis SA, Stathakopoulos DP, Papagelopoulos PJ, Badekas AC, Kaiser JH: Evaluation of pedicle screw position in thoracic and lumbar spine fixation using plain radiographs and computed tomography. A prospective study of 35 patients. Spine (Phila Pa 1976) 24(18):1926-1929, 1999

23. Schols AM, Wouters EF: Nutritional abnormalities and supplementation in chronic obstructive pulmonary disease. Clin Chest Med 21(4): 753-762, 2000

24. Sezdi M, Sonmezoglu M, Tekeli O, Ulgen Y, Emerk K: Changes in electrical and physiological properties of human blood during storage. Conf Proc IEEE Eng Med Biol Soc 7: 6710-6713, 2005

25. Shi YB, Binette M, Martin WH, Pearson JM, Hart RA: Electrical stimulation for intraoperative evaluation of thoracic pedicle screw placement. Spine (Phila Pa 1976) 28(6): 595-601, 2003

26. Vaccaro AR, Rizzolo SJ, Balderston RA, Allardyce TJ, Garfin SR, Dolinskas C, An HS: Placement of pedicle screws in the thoracic spine. Part II: An anatomical and radiographic assessment. J Bone Joint Surg Am 77(8): 1200-1206, 1995

27. Welch WC, Rose RD, Balzer JR, Jacobs GB: Evaluation with evoked and spontaneous electromyography during lumbar instrumentation: A prospective study. J Neurosurg 87(3): 397-402, 1997

28. West JL 3rd, Ogilvie JW, Bradford DS: Complications of the variable screw plate pedicle screw fixation. Spine (Phila $\mathrm{Pa} 1976$ ) 16(5): 576-579, 1991

29. Xu R, Ebraheim NA, Ou Y, Yeasting RA: Anatomic considerations of pedicle screw placement in the thoracic spine. Roy-Camille technique versus open-lamina technique. Spine (Phila Pa 1976) 23(9): 1065-1068, 1998 